\title{
Edyta Pagel
}

\author{
Szkoła Wyższa im. Bogdana Jańskiego
}

\section{Metody badań komunikatów wizualnych}

\section{Methods of testing visual messages}

\section{STRESZCZENIE:}

Jedną z najistotniejszych cech kultury popularnej jest jej wizualny charakter, dominacja obrazów nad przekazami słownymi, wzrokocentryzm. Współczesna cywilizacja stała się cywilizacją ikoniczną, w której nadrzędne jest to, co widzialne, wzrok jest faworyzowany jako podstawowy zmysł. Specyfiką ikonosfery kultury popularnej jest jej rozrywkowy charakter, zabawa, intrygowanie, uwodzenie i mamienie odbiorcy. Ikonosfera, dzięki multiplikacji, ale też kolorowi jest dynamiczna, ściąga na siebie społeczną uwagę, wpływa na ludzkie działania, zachowania, postawy i role społeczne. Ma ona spełniać głównie funkcję estetyzującą, która często odrealnia rzeczywistość i manipuluje odbiorcami. Ikonosfera operuje obrazami i symbolami, które są wieloznaczne, nie zawsze mają swoje odpowiedniki słowne, lub są trudne do przetłumaczenia na słowa. We współczesnej humanistyce nastąpił zwrot ikoniczny (G. Bohm, J.C. Alexander), nazwany również zwrotem piktorialnym (W.J.T. Mitchell), co znaczy, że obrazy tworzą punkt szczególnego zorientowania intelektualnych dociekań.

Stają się one centralnym tematem dyskusji w naukach humanistycznych, tak jak dawniej język, co doprowadziło do utworzenia studiów nad kulturą wizualną (Visual Culture Studies) i dyskusji na temat złożonych metod badania komunikatów wizualnych. Temu właśnie zagadnieniu został poświęcony niniejszy artykuł.

SŁOWA KLUCZOWE: wizualność, obraz, komunikat, dzieło sztuki, semiologia, znak, kod, metodologia, interpretacja, reinterpretacja

\section{ABSTRACT:}

One of the most important features of popular culture is its visual nature, the dominance of images over transfers verbal. Modern civilization has become an iconic civilization in which the paramount is what visible sight is favored as the primary sense. The specificity iconography of popular culture is its entertaining nature, fun, puzzling, grooming and deceiving the recipient. Iconosphere, by multiplication, but also the color is dynamic, draws the attention to social influences on human actions, behavior, attitudes and social roles. It's mainly a function aestheticizing meet that often unreal reality and manipulates the audience. Iconosphere operates images and symbols, that are ambiguous do not always have their counterparts verbal or are difficult to translate into words. In modern humanities occurred iconic phrase (G. Bohm, J. C. Alexander), which means that the images are formed special point orientation of intellectual inquiry. They become a central topic of discussion in the humanities, as formerly language, which led to the creation of visual culture studies (Visual Culture Studies) and discussion on complex research methods visual messages, which takes the author in this article.

\section{KEYWORDS:}

visuality, image, communique, work of art, semiology, sign, code, methodology, interpretation, reinterpretation 
$\mathrm{D}$ efiniując obraz Maurice Denis w 1890 r. pisał, że zanim stanie się on określoną figuracją, jest płaską powierzchnią pokrytą kolorami, uporządkowanymi wedle przyjętej przez artystę zasady ${ }^{1}$. Kiedy spojrzy na obraz odbiorca i podda go interpretacji, wówczas staje się on pełnym dziełem, nie tylko estetycznym doznaniem, ale przekazem wielorakich informacji.

Umiejętność interpretowania obrazów człowiek doskonali w miarę upływu lat. Dwuletnie dziecko potrafi rozpoznać i nazwać wiele przedmiotów przedstawionych na obrazkach, ale nie umie opisać czynności, ponieważ tę umiejętność nabywa około szóstego roku życia. Nie potrafi również ich interpretować, gdyż zdolność interpretacji kształtuje się około jedenastego roku życia. Znaczy to, że na każdym etapie rozwojowym człowiek inaczej odczytuje komunikaty wizualne, wraz z wiekiem „dojrzewa” do zrozumienia ich często wieloznacznej treści. Także według teorii S. Wortha i L. Grossa występują różne etapy rozwoju strategii interpretacji $^{2}$. Na wczesnym etapie rozwoju dzieci używają atrybucyjnych strategii interpretacji. Są przekonane, że wydarzenia przedstawione na obrazkach są prawdziwe, bo same ich doświadczyły. Starsze dzieci zaczynają sobie zdawać sprawę, że obrazki nie przedstawiają naturalnego, prostego zapisu danego wydarzenia. Jest to implikacyjno-inferencyjna strategia interpretacji.

Typ obrazowania, przyjęty w danej kulturze, jest ściśle związany z jej całym systemem wiedzy. Znaczenie obrazu dla odbiorcy w dużym stopniu zależy od jego inteligencji, zasobów wiadomości i doświadczeń wizualnych oraz ogólnosemiotycznych. Kto nie widział nigdy danego przedmiotu, nie potrafi go rozpoznać na obrazie. Według Hansa Beltinga tajemnica obrazu polega na tym, że w sposób nierozerwalny splataja się w nim obecność i nieobecnośćs. Ludzka percepcja ma jednak zdolność nieustannego dopasowywania się do nowych technik obrazowych.

Dzieło sztuki funkcjonuje wyłącznie w interpretacjach, które pojawiają się na jego temat. Umberto Eco uważa, że artysta tworząc daną formę czyni ją otwartą na nieskończenie wiele możliwych interpretacji ${ }^{4}$. Nieskończenie wiele, ponieważ każdy człowiek ma własny styl widzenia, rozumowania. A jak stwierdził Edward

${ }^{1}$ E. Grabska, H. Morawska, Artyści o sztuce od van Gogha do Picassa, PWN, Warszawa 1977, s. 70.

${ }^{2}$ H. Belting, Antropologia obrazu. Szkice do nauki o obrazie, tłum. M. Bryl, Universitas, Kraków 2007, s. 39.

${ }^{3}$ Tamże, s. 39.

${ }^{4}$ U. Eco, Sztuka, Wydawnictwo m, Kraków 2008, s. 29. 
Kasperski interpretacje generują niejako same siebie. Fakt pojawienia się nawet jednej z nich uzasadnia pojawienie się nieskończenie wielu potencjalnych interpretacji ${ }^{5}$. Z kolei Ernst Gombrich twierdzi, że interpretacji włożonej przez twórce przekazu musi zawsze odpowiadać interpretacja widza ${ }^{6}$, z czym trudno się zgodzić. Z pewnością pierwszym etapem interpretacji dzieła sztuki może być poszukiwanie pierwotnej intencji autora, ponieważ każdy obraz zawiera w sobie interpretacje rzeczywistości jego twórcy. Jednak nie zawsze interpretacja twórcy przekazu odpowiada interpretacji odbiorcy ze względu na opisywany już przez autorkę problem z izotypem. Często interpretacja danego obrazu jest niezależna od zamierzeń autora. $\mathrm{Z}$ drugiej strony, Gombrich sugeruje, że należy oglądać obraz bez żadnego nastawienia, przerzucając wzrok z jednej części płótna na inną.

Podobnie jak Eco uważa Rudolf Wittkower pisząc, że znaczenie dzieła sztuki pozostaje otwarte dla interpretacji ${ }^{7}$. Bez niej obrazy, jak i przedmioty, są tylko nieczytelnymi kształtami i plamami kolorów. Wittkower wyróżnił cztery pozio-

\section{Typ obrazowania, przyjęty w danej kulturze, jest ściśle związany z jej całym systemem wiedzy.}

my znaczeń zawartych w większości symboli wizualnych, które należy poddać interpretacji: dosłowną identyfikację przedmiotową, dosłowną identyfikację tematyczną, odczytanie treści oraz odczytanie ekspresji ${ }^{8}$. W pierwszym poziomie interpretacji musimy odgadnąć przedstawiony przedmiot np. książkę, płot, kwiat, co autor nazywa również zbadaniem znaczenia przedmiotowego. Interpretacja racjonalna różni się od emocjonalnej, ale mogą one wzajemnie na siebie oddziaływać. Racjonalna interpretacja może pobudzać reakcję emocjonalną i odwrotnie,

${ }^{5}$ E. Kasperski, Interpretacja, dyskurs i władza znaczeń. Szkic o zasadach interpretacji, „Słupskie Prace Filologiczne” 2005, s. 5.

${ }^{6}$ E. Gombrich, Obraz wizualny, w: Audiowizualność w kulturze. Zagadnienia i wybór tekstów, cz. I, red. S. Kuśmierczyk, Wyd. UW, Warszawa 2002, s. 144.

${ }^{7}$ R. Wittkower, Interpretacja symboli wizualnych, przeł. A. Morawińska, w: Symbole i symbolika, wybrał i wstępem opatrzył M. Głowiński, Czytelnik, Warszawa 1990, s. 339.

${ }^{8}$ Tamże, s. 340. 
emocjonalna reakcja często wpływa na racjonalną interpretację. Reakcje emocjonalne według Wittkowera mogą wynikać z rytuałów i przyzwyczajeń9. Emocjonalność odbioru czyni ze sztuki żywe dziedzictwo.

Jednak nie wszystko, co jest przedstawione na obrazie, musi coś oznaczać i nie wszystko musiało znaleźć się na nim nieprzypadkowo. Terence Wright uważał, że można mówić o trzech rodzajach spojrzenia na obraz fotograficzny, co warto również odnieść do wszystkich obrazów. Po pierwsze, można patrzeć na obraz na zasadzie patrzenia przez. Wówczas staje się on oknem, dziurką od klucza, przez którą widać rzeczywistość. Obraz tym samym nie jest prezentacją rzeczywistości, jej odzwierciedleniem, ale samą rzeczywistością. Po drugie, na obraz można patrzeć na zasadzie patrzenia na. Jest on wtedy środkiem komunikacji, nieistotne jest to, co widać, ale jaka jest symbolika tego, co widać i do jakich znaczeń ona odsyła. Po trzecie, na obraz można patrzeć na zasadzie za. Jest on wtedy odbitką kontekstu jego wykonania, jest wskaźnikiem i śladem reguł społeczno-kulturowych, które przesądziły o jego zaistnieniu i kształcie ${ }^{10}$. Jest też faktem, że istnieje subiektywne „odczucie”, którego nie można wyeliminować z widzenia czegoś ${ }^{11}$, a świadomość tego „odczucia” powinna w takim samym stopniu stanowić element rozumienia obrazów, jak interpretacja ich znaczenia, choć pełne ujęcie go w słowa jest niemożliwe.

Z kolei, według Mirce Eliadego tłumaczenie obrazu na język konkretu, sprowadzające go do jednej płaszczyzny interpretacji, to coś znacznie gorszego niż zniekształcenie, to unicestwienie obrazu, odrzucenie jako narzędzia poznania ${ }^{12}$.

Według Johna Bergera w interpretacji komunikatu wizualnego należy wziąć pod uwagę sposoby widzenia konkretnych widzów, patrzących w określony sposób ${ }^{13}$. Widzenie obrazu zawsze dokonuje się w określonym kontekście społecznym, który zapośrednicza jego wpływ. Zawsze też odbywa się w danym miejscu, np. muzeum, salon, ulica, a każde z nich ma swoją ekonomię spojrzenia, zasady jak widz powinien się zachować i jak patrzeć na obraz. Z tego wynika, że

${ }^{9}$ Tamże.

${ }^{10}$ T. Wright, The Photography Handbook, Routledge, London 1999, s. 38.

${ }^{11}$ C. Van Eck, E. Winters, Introduction, w: Dealing with the Visual: Art History, Aesthetics and Visual Culture, Ashgate Aldershot 2005, s. 4.

${ }^{12}$ M. Eliade, Obrazy i symbole, Wydawnictwo KR, Warszawa 1998, s. 18.

${ }^{13}$ J. Berger, Sposoby widzenia, tłum. M. Bryl, Fundacja Aletheia, Warszawa 2008, s. 49. 
przedstawienia wizualne są w jakiś sposób multimodalne, czyli zawsze znaczą w relacji z tym, co je otacza.

Nie ma jednej metody badań nad wizualnością, różni badacze przywiązują wagę do różnych wytycznych. Jest ona badana przez m.in. interpretację kompozycyjną, semiologię, psychoanalizę, analizę dyskursu. Dzieła sztuki, jako dobra symboliczne, istnieja jedynie dla tych, którzy dysponują środkami pozwalającymi na ich zawłaszczenie, czyli na ich odkodowanie ${ }^{14}$.

Potęga obrazu jest w nim samym, w tysiącach spojrzeń, które jego powierzchnia przykuwa, i wynikającym z nich zwrocie, przesunięciu, zmianie biegu strumienia dyskursu ${ }^{15}$. Interpretacja kompozycyjna przedstawień wizualnych uznaje istnienie trzech obszarów, w ramach których tworzone są znaczenia: obszar wytwarzania obrazu, obszar samego obrazu, obszar, w którym obraz jest widziany przez różne publiczności ${ }^{16}$. Każdy z tych obszarów ma trzy aspekty, modalności: modalność technologiczną, kompozycyjną i społeczną. Wiele sporów wokół wizu-

\section{Ludzka percepcja ma jednak zdolność nieustannego dopasowywania się do nowych technik obrazowych.}

alności jest dyskusją na temat tego, które z obszarów i modalności są najistotniejsze oraz dlaczego.

Obszar wytwarzania to sposób i okoliczności wykonania przedstawień wizualnych, które wpływają na ich odbiór. Niektórzy uważają, że technologia użyta przy wytwarzaniu obrazu determinuje jego formę, znaczenie i sposób oddziaływania. W tym kontekście ważna jest również struktura kompozycji, gatunek, do którego należy obraz. Gatunek stanowi sposób klasyfikowania przedstawień wizualnych i dzielenie ich na pewne grupy. Z gatunkiem jest związany specyficzny

${ }^{14}$ P. Bourdieu, A. Darbel, The Love of Art: European Art Museums and Their Public, Polity Press, Cambridge 1991, s. 39.

${ }^{15}$ N. Bryson, Semiology and Visual interpretation, w: N. Bryson, M. A. Holly, K. Moxey (red.), Visual Theory: Painting and Interpretation, Polity Press, Cambridge 1991, s. 71.

${ }^{16} \mathrm{G}$. Rose, Interpretacja materiałów wizualnych. Krytyczna metodologia badań nad wizualnością, PWN, Warszawa 2010, s. 33. 
zestaw przedstawień przedmiotów i miejsc. Interpretując można odnieść obraz do innych przedstawień tego samego gatunku. Do tego obszaru wchodzi też teoria autorska, ważne jest to, co autor chciał przekazać. Dlatego należy odpowiedzieć na pytania: kto wykonał obraz, kiedy, gdzie, czy zrobiono go dla osoby trzeciej, jakie stosunki łączyły twórcę, właściciela obrazu i osobę przedstawioną, czy stosunki te wpłynęły na tematykę obrazu, od jakich technik i technologii było uzależnione jego wykonanie?

W obszarze samego obrazu (struktura kompozycyjna) należy stawiać następujące pytania: co zostało na nim pokazane, składowe obrazu, ich układ (organizacja przestrzenna), jaka jest materialna forma obrazu, czy jest elementem jakiegoś cyklu, które miejsce na obrazie przyciąga wzrok widza i dlaczego, jakich kolorów użyto, jakie związki wizualne zachodzą między składowymi obrazu, jak technologia wpłynęła na treść, do jakiego gatunku należy obraz, w jaki sposób wykorzystuje charakterystyczne cechy gatunku?

Z kolei, w obszarze dotyczącym odbiorczości ważna jest modalność społeczna i odpowiedzi na pytania: kim był pierwotny odbiorca obrazu, gdzie i jak był pierwotnie pokazywany, jak wygląda obieg obrazu, jak jest przechowywany, gdzie jest obecnie wystawiony, kim jest jego dzisiejszy odbiorca, jak umiejscowiony jest widz względem składowych obrazu (pozycja widza jest elementem sposobu widzenia obrazu), jaki związek wytwarza ta sytuacja, czy obrazowi towarzyszy tekst pisany, który sugerowałby jakąś interpretację, jakie konwencje stosuje się przy oglądaniu obrazów wykonanych w tej technologii, jak różne publiczności interpretują ten obraz ze względu na płeć, rasę, wiek? Obraz sugeruje konkretną pozycję widzowi przez zbliżenia, oddalenia, perspektywę, grę kolorem. Jak stwierdziła Michael Ann Holly, to właśnie umiejscowienie widza, które nazwała logiką figuracji, okazuje się najważniejsze z perspektywy oddziaływania obrazu i jego skutków. Zgodnie z prawami ustalonymi przez przestrzenna i czasowq organizację pola wizualnego, stoimy tam, gdzie dzieła mówiq nam, że mamy stać, i widzimy to, co zdecydują się nam wyjawićn ${ }^{17}$. Niejako ustalają one pozycję widza. Kąt, pod jakim odbiorca patrzy na obraz ma skutki, jeśli chodzi o jego odbiór. Ujęcia frontalne wciągają widza bardziej, niż ujęcia pod kątem. Odległość od obrazu też wpływa na odbiór, ważne, czy patrzy on z góry, czy do góry. Jeśli perspektywa obrazu

${ }^{17}$ M. A. Holly, Past Looking: Historical Imagination and the Rhetoric of the Image, Cornell University Press, New York1996, s. 9.

KULTURA - MEDIA - TEOLOGIA 36/2019 
umieszcza go tak, że patrzy z góry, to daje mu ona pewien rodzaj władzy. Odwrotnie, ma niższą pozycję w stosunku do tematu. Jeśli jego spojrzenie jest na tym samym poziomie, co temat przedstawienia, mamy do czynienia z relacją równości między widzem a tym, co przedstawione ${ }^{18}$.

Aby rozpoznać obraz trzeba mieć kompetencję w zakresie społecznie tworzonych kodów rozpoznawania, czym zajmuje się semiologia. $W$ analizie semiotycznej sztuk wizualnych chodzi nie tyle o interpretacje dzieł sztuki, ile o badanie tego, w jaki sposób stajq się one czytelne dla patrzących, badanie procesów, $w$ toku których widzowie nadaja znaczenie temu, co widzą ${ }^{19}$. Semiologia jako metoda interpretacji przedstawień wizualnych może przynieść wiele pożytku jako sposób myślenia o znaczeniu wizualnym. Koncentruje się ona na obszarze obrazu oraz jego modalności kompozycyjnej i społecznej. Semiologia bada znaki i ich dwa elementy: znaczone i znaczące. Znaczone to pojęcie lub przedmiot. Znaczące to dźwięk, obraz połączony ze znaczonym. De Saussure stwierdził, że nie istnie-

\section{Emocjonalność odbioru czyni ze sztuki żywe dziedzictwo.}

je konieczny związek między konkretnym znaczącym a odpowiadającym mu znaczonym.

Pierwszy etap analizy semiologicznej polega na zidentyfikowaniu podstawowych jednostek konstrukcyjnych obrazu, czyli znaków. Czasami według Bal i Brysona ${ }^{20}$ wyróżnienie znaków wizualnych okazuje się zadaniem dość trudnym, ponieważ nie ma jasnych granic między poszczególnymi częściami obrazu. Jeśli jednak uda się choć prowizorycznie wyróżnić pewne elementy obrazu jako znaki, można przystąpić do badania ich znaczeń. Jednak są wątpliwości czy teoria oparta na języku odpowiada specyfice przekazu wizualnego. Margaret Iversen wskazuje, że w relacji między znaczącym a znaczonym jest w wielu przedstawieniach

${ }^{18}$ G. Kress, van Leeuwen T., Reading Images: The Grammar of Visual Design, Routledge, London 1996, s. 146-148.

${ }^{19}$ M. Bal, N. Bryson, Semiotics and art history, "Art Bulletin" 73, 1991, s. 184.

${ }^{20}$ Tamże, s. 193-194. 
wizualnych inna, niż w znakach mowy czy pisma: Znaki językowe sq arbitralne $w$ tym znaczeniu, że między brzmieniem słowa a jego znaczeniem nie ma innego związku niż konwencjonalny, oparty na „kontekście” czy jakiejś zasadzie. Natomiast znaki wizualne w oczywisty sposób nie sq arbitralne, lecz „umotywowane” - za wyborem konkretnego znaczenia stoi zawsze jakiś powód. Słowo „pies” oraz obrazek przedstawiający psa nie znaczq w taki sam sposób, bezpiecznie będzie zatem przyjać, że teoria semiotyki oparta na językoznawstwie wykazuje wyraźne niedostatki, jeśli chodzi o całkowite wyjaśnienie znaczeń wizualnych ${ }^{21}$. Lepiej więc korzystać z typologii Charlesa Sandersa Peirce'a, ponieważ bogatsza typologia znaków u Peirce'a umożliwia rozważanie nad tym, jak funkcjonujq różne tryby znaczenia, podczas gdy model de Saussure'a mówi nam jedynie, jak działaja systemy arbitralnych znaków $^{22}$. Pierce zastosował metaforykę trójkąta, którego wierzchołki stanowią słowa klucze: reprezentacja (forma znaku), interpretacja (sens nadany znakowi), obiekt (rzecz, do której odwołuje się znak) ${ }^{23}$. Te pojęcia wzajemnie na siebie oddziałują i implikują znak obrazu, czyli jego określoną formę symboliczną.

Według Peirce’a istnieją trzy rodzaje znaków, wyróżniane w zależności od tego, jak rozumiana jest relacja między znaczącym a znaczonym: ikona - w znakach ikonicznych znaczące jest reprezentacją znaczonego dzięki temu, że wydaje się wykazywać do niego podobieństwo; znak indeksowy - związek między znaczonym a znaczącym wydaje się „naturalny” (ta „naturalność" jest często zdeterminowana kulturowo, np. smoczek - znak, gdzie można przewinąć niemowlaka); symbol - w znakach symbolicznych relacja między znaczącym a znaczonym ma charakter skonwencjonalizowany, lecz jednocześnie arbitralny ${ }^{24}$. Znaki działają w związkach z innymi znakami. Dzielimy je na syntagmatyczne (przyjmują znaczenie od znaków, które je otaczają w obrazie nieruchomym lub pojawiają się przed nimi czy po nich w sekwencji obrazów ruchomych) i paradygmatyczne, które zyskują znaczenie dzięki skontrastowaniu z innymi możliwymi znakami ${ }^{25}$. Znaki są złożone i mogą działać równocześnie na kilku płaszczyznach, czyli opis jednego znaku może wymagać użycia innych. Istnieją też inne sposoby opisu

${ }^{21}$ M. Iversen, Saussure v. Pierce: models for a semiotics of visual art, w: A.L. Rees, F. Borzello (red.) The New Art History, Camden Press, London 1986, s. 85.

22 Tamże.

${ }^{23}$ A. D’Alleva, Metody i teorie historii sztuki, Kraków 2008, s. 34-38.

${ }^{24}$ G. Rose, dz. cyt., s. 111-114.

25 Tamże. 
znaków. Można wprowadzić rozróżnienie ze względu na stopień ich symboliczności. Mogą być zatem denotatywne, czyli opisujące coś. Roland Barths uważa, że znaki działające na poziomie denotatywnym łatwo poddają się odkodowaniu ${ }^{26}$. Terminem związanym z denotacją jest diereza, czyli suma denotatywnych znaczeń obrazu. Obraz wizualny ukonkretnia tekst. Jak pisał Barthes zakotwicza go, tekst posiada według niego funkcję przekaźnikową ${ }^{27}$, ukierunkowuje, pozwala dokonać wyboru wśród innych interpretacji. Znaki mogą mieć też charakter konotatywny. Są nośnikami całej gamy znaczeń wyższego rzędu. Znaki konotatywne można podzielić na dwa rodzaje: znaki metonimiczne - tego rodzaju znak to coś, co kojarzy się z czymś innym i dzięki temu jest reprezentacją tego czegoś; znaki synekdochalne - taki znak to albo część czegoś, która zastępuje całość, albo całość będąca reprezentacją części.

Według Dana Sperbera liczba symboli jest zawsze większa od liczby wyjaśnieńn ${ }^{28}$, często mówimy, że wynikają one z tradycji i nie musimy ich wyjaśniać, albo stosujemy symbolikę i nie znamy do niej klucza, lub znają ją nieliczni. Dlatego autor uważa, że egzegeza symbolu może zawierać dwa składniki: tłumaczenie symbolu i uzasadnienie tego tłumaczenia ${ }^{29}$.

Uważa się, że obrazy zyskują znaczenie nie tylko dzięki własnym znakom, lecz także dzięki związkom ze znakami innych obrazów, np. na tej samej ekspozycji. Dlatego wielkie dzieła sztuki są pokazywane same w sali. Jest to relacyjność znaków, czyli to, co dany znak znaczy zależy od jego powiązań z innymi znakami, co utrudnia analizę znaków: znaczenie [rodzi się] właśnie w przechodzeniu od jednego znaku czy znaczenia do kolejnego, w jakimś perpetuum mobile, gdzie nie można określić początku, od którego zaczęła się semioza, ani też kresu, w którym się kończy, a pojawia pełne znaczenie znaków ${ }^{30}$.

Do badania wizualności można zastosować również psychoanalizę. Zwykle za jej pomocą bada się interpretację różnych aspektów przedstawień wizualnych, a zwłaszcza ich emocjonalne oddziaływanie na odbiorców (obszar odbiorczości). To, dlaczego jedne obrazy działają natychmiast i z wielką mocą na widzów, a inne

${ }^{26}$ R. Barthes, Image-Music-Text, Fontana, London 1977, s. 38.

27 Tamże, s. 38-41.

${ }^{28}$ D. Sperber, Ukryte znaczenia, w: M. Głowiński, Symbole i symbolika, Czytelnik, Warszawa 1990 , s. 112.

${ }^{29}$ Tamże, s. 115.

${ }^{30}$ M. Bal, N. Bryson, dz. cyt., s. 177. 
pozostawiają ich niewzruszonymi. Zygmunt Freud twierdził, że skopofilia - przyjemność patrzenia - stanowi jeden z podstawowych popędów, z którym rodzą się wszystkie widzące dzieci. Z kolei, Jacques Lacan dowodził, że pewne momenty widzenia oraz konkretne widoki są kluczowe z perspektywy kształtowania się podmiotowości i seksualności ludzi. Lacan stwierdził, że $w$ sferze widzialności wszystko jest pułapkq ${ }^{31}$. Według niego uczymy się widzieć w określony sposób i powtarzamy ten proces za każdym razem, gdy na coś patrzymy. Z kolei Mulvey twierdził, że wizualność różni się od płci. Wizualność aktywna jest charakterystyczna dla rodzaju męskiego, bierna dla żeńskiego. Według Griseldy Pollock: przedstawienie wizualne poddawane jest analizie [...] jako permanentnie niezbędne miejsce, w którym ciagle zachodzi proces kulturowy, jakim jest kształtowanie i funkcjonowanie podmiotu, konceptualizowanego jako niepewny i niestały ${ }^{32}$. Widz wnosi pewną podmiotowość, która rzutuje na oglądany przez niego obraz. Podmiot jest po części kształtowany subiektywnie poprzez to, jak widzi i jak skonstruowane jest jego pole widzenia. $W$ ten sposób to, co widziane rozumie się nie jako rzecz na zawsze ustaloną, lecz uzależnioną od rzutujących na nią stanowisk i schematów interpretacyjnych.

Wizualność można ujmować także jako rodzaj dyskursu. Określona wizualność będzie na przykład sprawiała, że pewne rzeczy widzi się w specyficzny sposób, podczas gdy inne stają się niewidzialne, a podmiot jest wytwarzany w obrębie tego właśnie pola widzialności i w tym też polu działa. Analizą dyskursu można się posługiwać badając to, jak obrazy tworzą konkretne wizje świata społecznego, czyli modalność społeczną w obszarze obrazu.

Inną metodę badań przedstawień obrazowych opracował Erwin Panofsky, jeden z najwybitniejszych historyków XX wieku (w 1955 r. sformułował jej wersję ostateczną). Powstała ona dla potrzeb historii sztuki, jako narzędzie analizy europejskiej kultury wysokiej, dlatego powoduje konieczność wprowadzenia wielu modyfikacji do metody. Ikonografia zajmuje się analitycznym opisem i klasyfikacją, ikonologia zaś jest próbą syntetycznej interpretacji.

${ }^{31}$ J. Lacan, The Four Fundamental Concepts of Psychoanalysis, Hogarth Press, London 1977, s. 93.

${ }^{32}$ G. Pollock, Art, w: E. Wright (red.) Feminism and Psychoanalysis: A Critical Dictionary, Blackwell, Oxford 1992, s. 10. 
Dla Panofsky'ego głównym zadaniem badacza sztuki staje się interpretacja. Pisał: widzenie jest fizjologicznym procesem odbierania wizualnych wrażeń, który jako taki nie zmienia się $w$ przebiegu historycznym. Zmienia się natomiast proces interpretacji tego, co zobaczone, w sensie wyboru estetycznego. Aktu tego dokonuje człowiek poprzez swe władze psychiczne. Jest to już proces psychologiczny, w którym wyraża się stosunek psychiki ludzkiej do świata widzialnego ${ }^{33}$. Panofsky wyróżnił trzy poziomy znaczenia dzieła sztuki. Pierwsza warstwa znaczenia dotyczy treści przedmiotowej, wyrazowej, składającej się na świat motywów artystycznych (pierwotnej, naturalnej, oczywistej) w przedstawionej w dziele sztuki formie widzialnej: układzie linii, brył, kolorów. Odbiorca rozpoznaje i identyfikuje konkretne rzeczy (drzewo), zjawiska (burza) i postaci. Tę interpretację semantyczną pierwszego stopnia Panofsky nazwał preikonograficzną. Aby jej dokonać, w większości przypadków wystarczy praktyczne doświadczenie życiowe, ale niejednokrotnie ze względu na historyczne zmienne sposoby obrazowania niezbędnym warunkiem poprawnego odczytania obrazu jest posiadanie wiedzy na temat historii stylów.

Drugi poziom znaczenia, według Panofsky’ego, dotyczy treści wtórnych (umownych, konwencjonalnych) i otwiera przed odbiorcą bogaty świat mitów, alegorii, symboli. Taka analiza ma charakter rozumowy, a nie instynktowny, jest domeną „ekspertów”, ponieważ trzeba znać źródła, literaturę, historię. Postępując tak łączymy motywy artystyczne i kombinacje artystycznych motywów (kompozycje) z tematami lub pojęciami. Motywy tak rozpoznawane, jako wykładniki wtórnego lub umownego znaczenia, można nazwać obrazami, a kombinacje obrazów tym, co dawni teoretycy sztuki określali jako invenzioni. [...] Identyfikacja takich obrazów, opowieści i alegorii należy do dziedziny określanej zwykle jako „ikonografia”34.

Trzeci etap interpretacji - interpretacja ikonologiczna - wykracza poza zmienne, intencjonalne (zamierzone przez twórcę) treści dzieła sztuki i skupia się na tzw. znaczeniu wewnętrznym (istotą, treścią głęboką albo faktyczną). To znaczenie wewnętrzne lub treść, składające się na świat wartości symbolicznych. Badane dzieło jest ujmowane jako historyczny dokument cywilizacji, zjawisko

${ }^{33}$ Cyt. za: J. Białostocki, Posłowie, w: E. Panofsky, Studia z historii sztuki, PIW, Warszawa 1971, s. 390.

${ }^{34}$ E. Panofsky, Studia z historii sztuki, PIW, Warszawa 1971, s. 13. 
kulturowe, symptom, kulturowy objaw przemian historycznych, które odbijają się w specyficznych formach symbolicznych i osobowości twórcy dzieła.

Według Panofsky'ego siła interpretacji ikonograficznej opiera się na intertekstualności. Nie istnieje jedna czy też „poprawna” odpowiedź na pytanie „co znaczy ten obraz?” lub „co ten obraz mówi?”. Nie istnieje bowiem prawo gwarantujace, że rzeczy będq posiadać "jedno prawdziwe znaczenie” ani że znaczenia nie będq się zmieniać w czasie. Stąd, działania na tym obszarze w nieunikniony sposób maja charakter interpretacji - nie decyzji, kto ma „rację, a kto się „myli”, lecz dyskusji pomiędzy tak samo wiarygodnymi, choć czasem konkurującymi ze sobq i zwalczajacymi się, znaczeniami i interpretacjami ${ }^{35}$.

Ważnych wskazówek dotyczących interpretacji symboli wizualnych w dziełach sztuki udzielił Rudolf Wittkower. Punktem wyjścia były dla niego możliwości interpretacji racjonalnej, a punktem dojścia - interpretacja emocjonalna (intuicyjna), ale nie osobista. Pisał: intuicyjne podejście bardzo rzadko pozwala pochwycić znaczenie, jakie artysta zamierza nadać symbolom. Tymczasem to właśnie ten emocjonalny współudział czyni ze sztuki żywe dziedzictwo. Zatem do interpretatora należy badanie przyczyn takiego emocjonalnego zaangażowania i podejmowanie prób wyjaśnienia nieprzerwalnego procesu tworzenia, degeneracji i regeneracji symboli wizualnych. Musi on interpretować „dzieje życia” symboli ${ }^{36}$. Wittkower wyróżnił cztery poziomy znaczeń zawartych prawie w każdym symbolu wizualnym (prawie, bo w sztuce nowoczesnej często brakuje któregoś z poziomów). Są to: dosłowna identyfikacja przedmiotowa, dosłowna identyfikacja tematyczna, odczytanie treści i odczytanie ekspresji. Poziom identyfikacji przedmiotowej można utożsamić z opisem preikonograficznym według Panofsky’ego. Ważna jest tu identyfikacja konkretnych przedmiotów, niezależna od sposobu wykonania, lecz w znacznej mierze uwarunkowana kulturową kompetencją odbiorcy i tradycjami kultury wizualnej. Kolejny poziom interpretacji racjonalnej wiąże się z rozpoznawaniem konkretnych tematów (u Panofsky'ego analiza ikonograficzna), będących rodzajem konwencjonalnego języka atrybutów, alegorii i scen, odwołujących się do tradycji słownej, tekstów pisanych. Należy wziąć pod uwagę tekst, kontekst

${ }^{35}$ S. Hall, Introduction, w: S. Hall (red.), Representation: Cultural Representations and Signifying Practices, Sage, London 1997, s. 9.

${ }^{36}$ R. Wittkower, Interpretacja symboli wizualnych, w: M. Głowiński (red.), Symbole i symbolika, tłum. A. Morawińska, Czytelnik, Warszawa 1990, s. 352. 
społeczny, tradycję, do której odwołuje się temat dzieła. Nie każde dzieło sztuki charakteryzuje się tym, że zawiera w sobie wszystkie poziomy znaczeń symbolu według Wittkowera czy warstwy znaczenia według Panofsky’ego. Obaj badacze zauważyli, że w przypadku na przykład malarstwa rodzajowego, martwej natury, poziom treści wtórnej lub umownej w ogóle nie występuje. A zatem, w interpretacji od razu, pomijając analizę ikonograficzną, przechodzimy od opisu rzeczy i zdarzeń do fazy interpretacji ikonologicznej.

Jak widać z powyższych rozważań, występuje wiele często złożonych metod badania komunikatów wizualnych. Wobec tego, interesujące wydają się wspólne przedsięwzięcia socjologów obrazów, semiotyków i językoznawców, którzy wymyślili edukacyjny ruch umiejętności wizualnych (visual literacy). Głównym celem ruchu jest wprowadzenie specjalnych kursów czytania obrazów (zarówno ruchomych, jak i nieruchomych) dla dzieci i dorosłych. Wynika to z tego, że komunikacja zapośredniczona przez elektroniczne media wizualne staje się wszechobecna i w związku z tym jej uczestnicy powinni nauczyć się dostrzegać jej przejawy i dekodować komunikaty emitowane przez media. Nauka odczytywania komunikatów wizualnych miałaby być orężem w walce z działaniami manipulacyjnymi obrazów medialnych. Celem analizy materiału wizualnego byłoby przetłumaczenie (zdekodowanie) elementów obrazowych na język komunikacji werbalnej.

\section{BIBLIOGRAFIA}

Bal M., Bryson N., Semiotics and art history, "Art Bulletin”, nr 73, 1991.

Barthes R., Image-Music-Text, Fontana, London 1977.

Belting H., Antropologia obrazu. Szkice do nauki o obrazie, tłum. M. Bryl, Universitas, Kraków 2007.

Berger J., Sposoby widzenia, tłum. M. Bryl, Fundacja Aletheia, Warszawa 2008.

Bourdieu P., Darbel A., The Love of Art: European Art Museums and Their Public, Polity Press, Cambridge 1991.

Bryson N., Semiology and Visual interpretation, w: N. Bryson, M. A. Holly, K. Moxey (red.), Visual Theory: Painting and Interpretation, Polity Press, Cambridge 1991.

D’Alleva A., Metody i teorie historii sztuki, Kraków 2008.

Eco U., Sztuka, Wydawnictwo m, Kraków 2008.

Eliade M., Obrazy i symbole, Wydawnictwo KR, Warszawa 1998.

Gombrich E., Obraz wizualny, w: Audiowizualność w kulturze. Zagadnienia i wybór tekstów, cz. I, red. S. Kuśmierczyk, Wyd. UW, Warszawa 2002. 
Grabska E., Morawska H., Artyści o sztuce od van Gogha do Picassa, PWN, Warszawa 1977. Hall S., Introduction, w: S. Hall (red.), Representation: Cultural Representations and Signifying Practices, Sage, London 1997.

Holly M.A., Past Looking: Historical Imagination and the Rhetoric of the Image, Cornell University Press, New York 1996.

Iversen M., Saussure v. Pierce: models for a semiotics of visual art, w: A.L. Rees, F. Borzello (red.) The New Art History, Camden Press, London 1986.

Kasperski E., Interpretacja, dyskurs i władza znaczeń. Szkic o zasadach interpretacji, „Słupskie Prace Filologiczne" 2005.

Kress G., van Leeuwen T., Reading Images: The Grammar of Visual Design, Routledge, London 1996.

Lacan J., The Four Fundamental Concepts of Psychoanalysis, Hogarth Press, London 1977.

Panofsky E., Studia z historii sztuki, PIW, Warszawa 1971.

Pollock G., Art, w: E. Wright (red.), Feminism and Psychoanalysis: A Critical Dictionary, Blackwell, Oxford 1992.

Rose G., Interpretacja materiałów wizualnych. Krytyczna metodologia badań nad wizualnością, PWN, Warszawa 2010.

Sperber D., Ukryte znaczenia, w: M. Głowiński, Symbole i symbolika, Czytelnik, Warszawa 1990.

Van Eck C., Winters E., Introduction, w: Dealing with the Visual: Art History, Aesthetics and Visual Culture, Ashgate Aldershot 2005.

Wittkower R., Interpretacja symboli wizualnych, przeł. A. Morawińska, w: Symbole i symbolika, wybrał i wstępem opatrzył M. Głowiński, Czytelnik, Warszawa 1990.

Wright T., The Photography Handbook, Routledge, London 1999, T. Wright, The Photography Handbook, Routledge, London 1999.

\section{Biogram}

Edyta Pagel - doktor nauk humanistycznych, kulturoznawca, animator kultury, antropolog widowisk i audiowizualności, pedagog. Absolwentka Wydziału Polonistyki UW i Instytutu Kultury Polskiej UW w Zakładzie Teatru i Widowisk. Interesuje się antropologią widowisk społecznych, antropologią codzienności, problematyką kultury popularnej, audiowizualnością oraz mediami jako elementami kultury popularnej. 